\title{
Ingresso e permanência na Universidade: alunos com deficiências em foco
}

\section{Ingress and stay in the University: students with disabilities in focus}

\author{
Laura Ceretta Moreira ${ }^{1}$ \\ Maria Augusta Bolsanello ${ }^{2}$ \\ Rosangela Gehrke Seger ${ }^{3}$
}

\begin{abstract}
RESUMO
O estudo trata das políticas inclusivas inseridas na educação brasileira a partir da década de 1990 para os alunos com Necessidades Educacionais Especiais (NEE). Realiza uma breve apresentação dessas políticas na educação básica e, de forma mais específica, no ensino superior. Discute os principais dispositivos legais acerca da inclusão desse alunado no ensino superior, bem como alguns dos desdobramentos e implicações para a universidade pública. Utiliza como referência a trajetória da Universidade Federal do Paraná (UFPR), evidenciando os dispositivos legais e as principais ações institucionais que embasaram a implantação da inclusão dos alunos com NEE nesta universidade. Sete alunos foram entrevistados (três com cegueira, dois com deficiência física, um com deficiência múltipla e um com surdez), em sete cursos da UFPR, com o objetivo de conhecer a trajetória desses alunos na universidade e a sua relação com as ações e encaminhamentos institucionais no seu processo de inclusão. Após análise qualitativa dos dados extraíram-se os seguintes eixos de análise: perfil
\end{abstract}

${ }^{1}$ Professora da Graduação e da Pós-Graduação do Setor de Educação da Universidade Federal do Paraná. Coordenadora de Estudos e Pesquisas Inovadoras na Graduação (CEPIGRAD/ PROGRAD/UFPR). Doutora em Educação pela Universidade de São Paulo (USP). Brasil. E-mail: lauracm@ufpr.br

${ }^{2}$ Professora da Graduação e da Pós-Graduação do Setor de Educação da Universidade Federal do Paraná. Doutora em Psicologia Escolar e do Desenvolvimento Humano pela Universidade de São Paulo (USP). Brasil. E-mail: mabolsanello@ufpr.br

${ }^{3}$ Fonoaudióloga, assistente de administração da Coordenação de Estudos e Pesquisas Inovadoras na Graduação (CEPIGRAD), PROGRAD/UFPR. Mestranda em Educação (UFPR). E-mail: rgseger@hotmail.com 
dos alunos, ingresso e permanência na universidade, políticas inclusivas na universidade. Os dados coletados destacam as vivências e estratégias desenvolvidas pelos alunos para permanecer no ensino superior e a importância de apoios e recursos no ingresso e permanência na universidade. Por fim, evidencia a importância da implementação de políticas efetivas para garantir a inclusão desse alunado e o papel fundamental da universidade na defesa dos direitos dos alunos com deficiência.

Palavras-chave: políticas inclusivas; educação inclusiva; ensino superior; alunos com deficiências; alunos com necessidades educacionais especiais.

\begin{abstract}
The study examines inclusive policies included in the Brazilian education from the 1990s to students with special educational needs (SEN). It performs a brief presentation of these policies in basic education and, more specifically, in higher education. It discusses the main legal provisions concerning the inclusion of students in higher education, as well as some implications for Public Universities. It refers to the trajectory of the Federal University of Paraná (UFPR), showing the main legal provisions and institutional actions that supported the implementation of the inclusion of students with SEN at the University. Seven students were interviewed (three with blindness, two with physical disabilities, one with multiple disabilities and one with deafness), in seven courses in the UFPR, in order to know the trajectory of these students at the University and the institutional actions related to their process of inclusion. After qualitative data analysis the study draws the following lines of analysis: profile of students, enrolling and staying in the University, inclusive policies at the University. The collected data showed the experiences and strategies developed by students to stay in higher education and the importance of support and resources to enroll and stay in the University. Finally, it highlights the importance of implementing effective policies to ensure the inclusion of those students and the university's role in defending the rights of students with disabilities.
\end{abstract}

Keywords: inclusive policies; inclusive education; higher education; students with disabilities; special educational needs.

Nos últimos vinte anos, conceitos como exclusão e inclusão educacionais tornaram-se cada vez mais recorrentes nas pesquisas, documentos oficiais e na fala de gestores e professores. Embora esses conceitos sejam usados em diversos contextos teóricos, e, muitas vezes, de modo impreciso. Pode-se afirmar que uma educação que busca primar pela qualidade de todos os alunos esbarra 
em inúmeras desigualdades (sociais, étnicas, raciais e de gênero) presentes na sociedade brasileira, que historicamente acumula um quadro de exclusões e contradições marcado por políticas públicas lábeis e inconsistentes.

Já ao se abordar a educação das pessoas com necessidades educacionais especiais ${ }^{4}$ (NEE), o cenário da exclusão é mais evidente, e é possível constatar que há um vazio histórico relacionado às políticas públicas destinadas a esse segmento da população. Esta é uma razão pela qual o processo de inclusão dessas pessoas, alavancado nas ultimas décadas, merece uma análise cuidadosa. Cumpre destacar que se reportará, ao longo deste texto, aos termos alunos/pessoas com necessidades educacionais especiais e alunos/pessoas com deficiência ${ }^{5}$, salientando-se que o estudo empírico efetuado e apresentado mais adiante se refere aos alunos com deficiência.

\section{Perspectivas da inclusão educacional no cenário nacional e seus desdobramentos no ensino superior}

Somente com a promulgação da Constituição Federal de 1988 é que o atendimento educacional especializado às pessoas com deficiência passa a ser ofertado preferencialmente na rede regular de ensino e, com a Lei de Diretrizes e Bases (LDB) 9.394/96, a educação especial passa a ser concebida como uma modalidade de educação escolar, como será visto a seguir.

A partir da década de 1990, concomitante às legislações nacionais, inúmeras conferências internacionais começam a repercutir diretamente na educação das pessoas com necessidades educacionais especiais. Destacam-se: a) a Conferência Mundial sobre Educação para Todos, que ocorreu no ano de 1990, em Jomtien, na Tailândia, que apresentava como meta primordial a revitalização do compromisso mundial de educar todos os cidadãos e contou com a presença de

${ }^{4}$ Segundo as Diretrizes Nacionais para a Educação Especial CNE/2001, são considerados alunos com necessidades educacionais especiais aqueles que apresentam deficiências (mental, visual, auditiva, física/motora e múltiplas); condutas típicas de síndromes e quadros psicológicos, neurológicos ou psiquiátricos; bem como de alunos que apresentam altas habilidades/superdotação (BRASIL, 2001).

${ }^{5}$ De acordo com a Política de Educação Especial na Perspectiva da Educação Inclusiva (BRASIL, 2008, p. 9), pessoa com deficiência é aquela que tem impedimentos de longo prazo, de natureza física, mental ou sensorial que, em interação com diversas barreiras, pode ter restringida sua participação plena e efetiva na escola e na sociedade. 
representantes de cento e cinquenta e cinco governos de diferentes países; b) a Conferência Mundial sobre Necessidades Educativas Especiais, representando noventa e dois países e vinte e cinco organizações internacionais, que reunidos em Salamanca, Espanha, em junho de 1994, reafirmaram o compromisso em prol da Educação para Todos e a necessidade de garantir a educação para as crianças, jovens e adultos com necessidades educativas especiais no quadro do sistema regular de educação. Desta conferência emana a Declaração de Salamanca; c) mais recentemente, a $48^{\text {a }}$ Conferência Internacional sobre Educação da UNESCO, ocorrida em 2008, em Genebra e que reuniu ministros da Educação, chefes de delegação e delegados dos 153 Estados-Membros, bem como representantes de 20 organizações intergovernamentais, $25 \mathrm{ONGs}^{6}$, fundações e outras instituições da sociedade civil. Esta Conferência teve a Educação Inclusiva como um dos seus grandes temas.

Esta breve contextualização demonstra o grande número de países signatários das conferências e que a decorrência direta foi a incorporação de seus princípios nos sistemas educacionais. Segundo Odeh (2000), as recomendações internacionais foram decisivas para a criação de políticas públicas que visavam à inclusão na escola e que foram prontamente absorvidas pelos quadros legais dos países da América Latina, embora sua regulamentação fosse acontecendo de maneira lenta e subjetiva, de acordo com as regras legislativas dos países. A consequência desse processo é uma "integração não-planejada", que tem início na educação básica com o acesso dos alunos com necessidades educacionais nas escolas regulares.

Neste sentido, Almeida (2002) adverte que atualmente o acesso ao ensino fundamental no Brasil está praticamente assegurado a todas as crianças e jovens.

No entanto, a abertura da escola não veio acompanhada de transformações capazes de alterar suas formas de organização e funcionamento, de assegurar condições de trabalho, salário e formação dos professores, comprometendo sua mudança qualitativa. A permanência na escola graças apenas à ausência de reprovação ao longo do ensino fundamental não está assegurando aos alunos uma aprendizagem efetiva. A manutenção das práticas educativas, da estrutura e da cultura tradicionais faz com que a escola ofereça um ensino aligeirado, contribuindo para preservar a situação de exclusão vivida pelos segmentos menos favorecidos economicamente. (ALMEIDA, 2002, p. 63).

\footnotetext{
${ }^{6}$ Organizações não governamentais.

${ }^{7}$ Termo usado por Odeh (2000).
} 
É nítido que o sistema educacional, a partir da década de 1990, está legalmente amparado no discurso inclusivo, nos princípios democráticos de igualdade, equidade e diversidade. No entanto, apesar da importância dos instrumentos legais, estes por si só não garantem práticas inclusivas na educação, muitas demonstrando distanciamento das proposições teóricas e legais.

Do mesmo modo que a proposta da inclusão na educação básica precisa ter uma organização pedagógica planejada, devidamente financiada para assegurar os apoios e recursos físicos, humanos e materiais aos alunos com necessidades educacionais especiais, o ensino superior necessita das mesmas condições, conforme se verá no decorrer deste estudo.

O movimento pela inclusão de alunos com NEE no ensino superior, assim como na educação básica, começa a emergir na década de 1990 por meio do aparato legal.

No Brasil, a primeira iniciativa por parte do Ministério da Educação (MEC), por meio da Secretaria de Educação Especial (SEESP), com relação ao aluno com necessidades educacionais especiais no Ensino Superior se deu através da Portaria $\mathrm{n}^{\mathrm{o}}$ 1.793/94, que recomendava a inclusão da disciplina "Aspectos Ético-Político-Educacionais da Normalização e Integração da Pessoa Portadora de Necessidades Especiais", prioritariamente nos cursos de Pedagogia, Psicologia e demais licenciaturas. Na prática, esta recomendação teve pouco impacto na grade curricular dos cursos de formação em Pedagogia e Psicologia, como demonstra Chacon (2001), ao analisar 58 grades curriculares desses cursos. O autor evidenciou que apenas 13 apresentavam alterações, o que significa 22,5\% dos cursos estudados.

A segunda iniciativa ocorreu em 1996, por meio do Aviso Circular n ${ }^{\circ} 277$ $\mathrm{MEC} / \mathrm{GM}^{8}$ que solicita das Instituiçoes de Ensino Superior (IES) a viabilização de condições de acesso aos candidatos com deficiências em seus concursos vestibulares e que as Instituiçoes desenvolvam ações que possibilitem a flexibilização dos serviços educacionais, de infraestrutura e de capacitação de recursos humanos, de modo que seja atendida uma permanência de qualidade a esses alunos.

Em 1999, é instituída a Portaria n. ${ }^{\circ} 1.679 / 99$ que trata dos requisitos de acessibilidade às pessoas com deficiências para instruir processos de autorização e de reconhecimento de cursos e de credenciamento de instituições. Também foi aprovado o Decreto n. ${ }^{\circ} 3.298 / 99^{9}$ que estabelece às IES a necessidade de adaptar as provas e conceder os apoios necessários, previamente solicitados pelo aluno com deficiência, inclusive tempo adicional para a realização das provas,

\footnotetext{
${ }^{8}$ Gabinete Ministerial.

${ }^{9}$ Regulamenta a Lei $n .{ }^{\circ} 7.853 / 89$.
} 
conforme as características da deficiência. O referido Decreto responsabiliza ainda o Ministério da Educação como responsável por expedir instruções para que os programas de Educação Superior incluam nos seus currículos conteúdos, itens ou disciplinas relacionados ao estudante com deficiência. Este aspecto aparece na Resolução CNE/CP No $1 / 2002^{10}$, que estabelece as Diretrizes Curriculares Nacionais para a Formação de Professores da Educação Básica em nível superior, nos cursos de licenciatura e de graduação plena. Ao discorrer sobre a construção dos projetos pedagógicos dos cursos de formação, a dita Resolução afirma que os mesmos deverão ter conhecimentos sobre as especificidades dos alunos com necessidades educacionais especiais.

Em 2005, é lançado o Incluir (Programa de Acessibilidade na Educação Superior), pelo Ministério da Educação, e está em vigência até a presente data. Nos dois primeiros anos (2005 e 2006) este programa objetivava principalmente criar possibilidades para que as IFES ${ }^{11}$ organizassem propostas de ações voltadas ao acesso ao ensino superior. Já a partir de 2007, passou a integrar as ações propostas pelo $\mathrm{PDE}^{12}$ e incentivar a criação e/ou fortalecimento dos Núcleos de Acessibilidade nas IES.

Vale destacar que também em 2005, o Decreto Federal 5.626/05 instituiu um novo cenário político com relação ao reconhecimento da diferença linguística dos surdos. Para tanto, insere a disciplina de Libras como obrigatória nos cursos de formação de professores para o exercício do magistério, em nível médio e superior, e nos cursos de Fonoaudiologia. De igual forma, constituiu a disciplina de Libras como optativa nos demais cursos de educação superior e na educação profissional.

Em 2008, a Política Nacional de Educação Especial na Perspectiva da Educação Inclusiva, evidencia que a transversalidade da educação especial no ensino superior deve ocorrer por meio de ações que desencadeiem o acesso, a permanência e a participação dos alunos. Para tal, o planejamento e a organização de recursos e serviços para a viabilização da acessibilidade arquitetônica, das comunicações, dos sistemas de informação, dos materiais didáticos e pedagógicos devem ser disponibilizados nos processos seletivos e no desenvolvimento de todas as atividades que envolvam o ensino, a pesquisa e a extensão (BRASIL, 2008).

Moreira (2004) evidencia que apesar dos movimentos pela inclusão das pessoas com deficiência, os censos educacionais da década de 1990 não revela-

\footnotetext{
${ }^{10}$ Conselho Nacional de Educação/Conselho Pleno.

${ }^{11}$ Instituições Federais de Ensino Superior.

${ }^{12}$ Plano do Desenvolvimento da Escola, criado pelo MEC para o aperfeiçoamento da gestão escolar democrática e inclusiva.
} 
ram o número de alunos com deficiência no ensino superior brasileiro. Esta falta de dados oficiais denotava a invisibilidade desse alunado, impossibilitando, até mesmo, chegar a indicativos mais concretos sobre sua real situação educacional e, por consequência, direcionar de forma mais precisa políticas inclusivas. Somente a partir do Censo Educacional de 2000, é contemplado o número de alunos com deficiências (física, auditiva, visual) nas IES do país. Naquele momento eram em número de 2.155. Em 2005, este número sobe para 6.022 alunos, ou seja, ocorreu um aumento de 179,4\%, entre os anos de 2000 e 2005. Apesar dos números evidenciarem a exclusão de alunos com deficiência do cenário educacional, pode-se considerar um avanço o aumento desse percentual em cinco anos. Por outro lado, os dados do Censo (BRASIL, 2007) indicaram que o número de alunos com deficiência matriculados no ensino superior foi de 6.460. Todavia, Castro (2010) chama atenção que, do total de alunos matriculados no ensino superior em 2007, que totalizavam 4.880.381, apenas $0,13 \%$ apresentavam alguma deficiência.

\section{Políticas inclusivas de acesso e permanência ao aluno com deficiência na UFPR: dos dispositivos legais às ações institucionais}

Na Universidade Federal do Paraná podemos considerar que a Resolução do $\mathrm{CEPE}^{13} / \mathrm{UFPR}^{\circ}$ 27/91, responsável pela implantação das bancas especiais, pode ser considerada como a primeira iniciativa institucional de caráter mais inclusivo destinada ao ingresso de estudantes com deficiência na Instituição. Somente seis anos depois, em 1997, é criado o Grupo de Trabalho sobre Pessoas com Necessidades Especiais da UFPR (GTPNE) ${ }^{14}$, que ficou sediado na Pró-Reitoria de Graduação e Educação Profissional (PROGRAD), e era composto por representantes dos nove setores existentes naquele momento na UFPR, da Escola Técnica desta Universidade e da PROGRAD. Segundo Moreira (2000), o Grupo de Trabalho sobre Pessoas com Necessidades Especiais (GTPNE) objetivava discutir, elaborar, propor e assessorar a implementação de ações que contemplassem a inclusão formal ou informal da temática no âmbito dos cursos de graduação e da Escola Técnica, além de incentivar e promover atividades de extensão e de pesquisa, voltadas para a formação de profissionais capacitados

${ }^{13}$ Conselho de Ensino, Pesquisa e Extensão.

${ }^{14}$ Motivado pelo Aviso Circular MEC/GM n 277. 
a trabalhar com a demanda de alunos com necessidades especiais nas variadas áreas de conhecimento na UFPR.

É apenas em 2006 que ocorre a criação do NAPNE (Núcleo de Apoio às Pessoas com Necessidades Especiais $)^{15}$ e a UFPR passa a institucionalizar de forma mais efetiva uma política para essa demanda. Em linhas gerais, este Núcleo busca alternativas de inclusão (acesso e permanência) à comunidade universitária com NEEs (alunos com surdez, deficiência visual, física, múltipla, que apresentem dificuldades de aprendizagem ou altas habilidades/superdotação), além de colaborar com os professores na organização de apoios e recursos didático-pedagógicos ao alunado com NEEs e desenvolver ações ${ }^{16}$ ligadas ao ensino, pesquisa e extensão relacionadas às necessidades educacionais especiais.

Uma importante ação do NAPNE ocorre a partir de 2007, quando passa a organizar juntamente com o Núcleo de Concursos (NC) as bancas especiais no concurso vestibular dos candidatos com necessidades educacionais especiais, bem como colaborar com as demandas relacionadas a essa área nos demais concursos organizados pelo NC.

Até o momento é a Resolução n. $^{0} 70 / 08-$ COUN $^{17}$ o último dispositivo institucional, aprovado na UFPR, que visa aprimorar as políticas de ingresso e de permanência de pessoas com deficiências, pois prevê a ampliação de investimentos na infraestrutura física e de pessoal e a destinação de 01 (uma) vaga em cada curso de graduação, de ensino profissionalizante e de ensino médio da UFPR para esse segmento.

Para coordenar o processo de acesso pelo sistema de vagas, foi criada em 2008 a banca de verificação ${ }^{18}$ composta por professores e técnicos da UFPR, tais como: pedagogo, educador especial, psicólogo, médicos de diversas especialidades, assistente social, fisioterapeuta, fonoaudiólogo, terapeuta educacional e intérprete de Libras.

${ }^{15}$ Sediado na PROGRAD e possui equipe constituída por pedagogos, professores especializados em deficiências, assistente social, fonoaudiólogo, técnico-administrativos, bolsistas e estagiários. Em 2008 foi inaugurado o LABNAPNE (Laboratório do Núcleo de Apoio às Pessoas com Necessidades Especiais), no setor Litoral da UFPR, que possui um laboratório de acessibilidade e trabalha de forma articulada com o NAPNE - campus Curitiba.

${ }^{16}$ Basicamente as ações do NAPNE são possíveis devido ao apoio financeiro institucional e do Programa Incluir, onde a UFPR nos anos de 2005, 2006, 2008, 2009 e 2010 recebeu recursos deste Programa por meio do projeto UFPR sem Barreiras: Incluir com qualidade.

${ }^{17}$ Conselho Universitário.

${ }^{18}$ A principal função da banca de verificação é a de analisar a documentação encaminhada pelos candidatos e realizar uma entrevista com os mesmos. O candidato que tem indeferido seu pedido para concorrer à vaga suplementar pode participar do concurso vestibular pela via da concorrência geral, ou se for o caso, pelas cotas sociais ou raciais. 
Em 2010, segundo dados coletados pelo NAPNE, há 36 alunos com deficiência na UFPR ${ }^{19}$. Deste total, 30 alunos estão no campus Curitiba, 4 no Setor Palotina e 2 no Setor Litoral.

Conhecer a trajetória desses alunos na Universidade e a relação das ações e encaminhamentos institucionais no seu processo de inclusão é uma forma de analisar e avaliar se as políticas inclusivas na instituição estão de fato se efetivando. Com este intuito, apresenta-se a seguir a trajetória metodológica utilizada, bem como os dados e considerações evidenciados a partir do relato de alunos que apresentam deficiência na UFPR.

\section{Método}

\section{Participantes}

A pesquisa foi realizada com alunos com deficiências frequentadores de cursos de graduação do campus Curitiba, da Universidade Federal do Paraná. Eram sete alunos, sendo três cegos, dois com deficiência física, um com deficiência múltipla e um com surdez. Os participantes foram selecionados de modo a contemplar todas as deficiências e diferentes setores da UFPR.

\section{Procedimentos}

Recorrer aos pressupostos da pesquisa qualitativa nesta investigação foi uma forma de visualizar a universidade como um espaço educacional e social que cria e recria conhecimentos, valores e significados. Por consequência, neste estudo, o diálogo com a realidade vivenciada por estudantes que apresentam deficiência foi possibilitado pelo uso da entrevista semiestruturada, a qual foi utilizada para analisar a trajetória de ingresso e permanência dos entrevistados na Universidade.

As entrevistas foram realizadas nas dependências da própria Universidade e em local reservado, com o prévio consentimento dos participantes. Foram gravadas e em seguida transcritas. Os dados foram analisados por meio de análise de conteúdo (BARDIN, 2004; ANDRÉ; LUDKE, 1986; MINAYO, 1992; BODGAN; BIKLEN, 2003). O procedimento da análise possibilitou a

${ }^{19} \mathrm{O}$ mapeamento realizado pelo NAPNE utiliza as seguintes categorias: surdez, visual, física/motora e múltipla. 
definição dos seguintes eixos norteadores da pesquisa: perfil dos participantes, ingresso e permanência na universidade, políticas inclusivas na universidade.

\section{Resultados e discussão}

Os relatos de todos os entrevistados neste estudo foram bem elucidativos para se compreender seu processo de inclusão, alguns dos desdobramentos das ações inclusivas institucionalizadas na universidade, bem como suas vivências na instituição.

O Quadro 1 a seguir apresenta dados do primeiro eixo de análise, que é o perfil dos participantes. Dos sete estudantes entrevistados, cinco são do sexo masculino e dois do sexo feminino. Dos três alunos que apresentam cegueira, um deles nasceu cego e os outros dois perderam a visão após o nascimento. Outros dois alunos possuem deficiência física, sendo uma oriunda de um acidente de trânsito e a outra decorrente de astrogripose, síndrome genética que ocasiona deformidades fixas nas articulações e músculos fracos, manifestando-se desde o nascimento. O outro aluno que tem deficiência múltipla apresenta baixa visão, mas seu comprometimento maior é a deficiência física, oriunda de osteogênese imperfeita, também conhecida como "ossos de vidro". Um dos alunos entrevistados possui surdez de moderada a severa, resultante de um quadro de pneumonia.

QUADRO 1 - DISTRIBUIÇÃO DOS PARTICIPANTES SEGUNDO O TIPO DE DEFICIÊNCIA E O ANO DE INGRESSO NA UNIVERSIDADE.

\begin{tabular}{|c|c|c|}
\hline Estudantes* $^{*}$ & Tipo de deficiência & $\begin{array}{c}\text { Ano de ingresso na } \\
\text { Universidade }\end{array}$ \\
\hline Rogério & Visual & 2006 \\
\hline Leonardo & Visual & 2009 \\
\hline Milton & Visual & 2009 \\
\hline Elaine & Física & 2010 \\
\hline Vilmar & Física & 2010 \\
\hline Jorge & Múltipla (Física/visual) & 2010 \\
\hline Livia & Surdez & 2010 \\
\hline
\end{tabular}

* Os nomes dos alunos são fictícios.

O Quadro 2 mostra que, dos sete participantes, quatro exercem atividades profissionais. Destes, um trabalha como voluntário e também possui uma bolsa permanência na Universidade. Outros dois estão envolvidos em atividades extracurriculares como estágio e bolsa de Iniciação Científica (IC). Apenas um dos alunos ainda não exerce atividades profissionais ou extracurriculares na Universidade. 
QUADRO 2 - DISTRIBUIÇÃO DOS PARTICIPANTES SEGUNDO SUAS ATIVIDADES PROFISSIONAIS E SUAS ATIVIDADES EXTRACURRICULARES DESENVOLVIDAS NA UNIVERSIDADE.

\begin{tabular}{|c|c|c|}
\hline Estudantes & Atividade Profissional & Atividade Extracurricular \\
\hline Rogério & Professor & Não participa \\
\hline Leonardo & Não exerce & Estagio extracurricular \\
\hline Milton & Não exerce & Não participa \\
\hline Elaine & Não exerce & Bolsa IC \\
\hline Vilmar & Empresário & Não participa \\
\hline Jorge & Trabalho voluntário & Bolsa permanência \\
\hline Livia & Auxiliar de administração & Não participa \\
\hline
\end{tabular}

Com relação ao ingresso na Universidade, conforme se evidencia no Quadro 1 , apenas um dos alunos teve seu processo de entrada na universidade no ano de 2006, ou seja, antes da aprovação da Resolução 70/08 do COUN, quando não havia ainda a opção da vaga suplementar para estudantes com deficiências. Dos outros seis alunos que tiveram esta opção, apenas dois optaram por esta via, ao contrário dos outros quatro. Com relação ao uso da banca especial, dos sete estudantes, apenas dois não participaram, sendo um deles por desconhecer a existência da mesma e o outro por acreditar que não necessitava da mesma.

Nas falas de todos os alunos foi possível observar a importância que a banca especial teve para eles:

Acho que foi algo inédito que fizemos na universidade, pois fiz as provas do vestibular da $1^{a}$ e da $2^{a}$ fase em formato digital Dox Vox e tinha aplicadores de prova que realizaram o trabalho de ledor e redator. Nas matérias especificas tais como inglês, química, física e matemática tinha aplicadores habilitados na área. (Leonardo)

A primeira vez que prestei a prova do vestibular não havia pedido a banca e não consegui terminar a prova, perdendo assim o processo seletivo. Por isso solicitei a banca em 2009 e achei ótimo, pois tive um atendimento diferenciado, com fala pausada sobre todas as orientações sobre a prova, avisos com relação ao término da realização da prova. Fui muito bem orientada e gostei muito do atendimento da banca especial. (Lívia)

Para Moreira (2004), a banca especial nos concursos vestibulares tem representado um mecanismo que atenua as dificuldades e observa as peculiaridades 
dos candidatos oferecendo condições mais igualitárias, já que deve estar atenta à acessibilidade, às ferramentas tecnológicas, aos apoios didático-pedagógicos alternativos e aos recursos humanos que atendam as especificidades dos candidatos. Como visto anteriormente, vem sendo solicitado às IES, há quase duas décadas, a organização de bancas especiais, que, embora não representem uma proposta de ingresso alternativo, é uma ação relevante que precisa ocorrer em todas as IES.

Embora as falas dos participantes tenham evidenciado a importância das bancas especiais, conteúdos de prova envolvendo gráficos, mapas, desenhos, dentre outros, podem se tornar inacessíveis, sobretudo para o candidato cego, pois não são transcritos pelo sistema Braille, lidos pelos softwares ou mesmo interpretados pelos ledores, de modo que possam ser compreendidos pelas pessoas cegas. Neste sentido, o estudante Rogério, apesar de afirmar que " $o$ atendimento das bancas especiais foi realizado com muita qualidade”, ressaltou também que "havia questões na prova muito complicadas, com grau de dificuldade bem complexo para quem não enxerga". Esta situação, como bem apontam Russell e Kavanaugh (2011), demonstra que os formuladores das provas precisam organizar as questões de modo que possibilitem a compreensão também desta demanda.

Outro aspecto com relação ao ingresso que merece ser enfatizado é quanto à existência da vaga destinada às pessoas com deficiência conforme está disposto na Resolução n. ${ }^{\circ}$ 70/08-COUN, da UFPR. Foi possível observar que os participantes desta pesquisa apresentam diferentes posicionamentos com relação à política de vaga suplementar.

Eu não achava justo concorrer pela vaga para deficientes. Achava que estaria tirando a vaga de outro e se não usada ficaria em aberto. Mas após ter participado do processo verifiquei que não é assim, e que o deficiente deve sim concorrer à vaga e usufruir dela. (Lívia)

Não concordo com as políticas de cotas para deficientes, pois acredito que são discriminatórias. (Jorge)

Eu sabia da existência da vaga especial, mas confiei no meu potencial e entrei pela concorrência geral. (Vilmar)

Eu não participei porque sempre estudei em escola particular não achei justo participar das cotas. (Leonardo) 
Verificou-se também em quatro dos sete depoimentos dos participantes que os mesmos - apesar das dificuldades que enfrentaram na educação básica e/ ou nas vivências diárias em decorrência da falta de adaptações, apoios e recursos pedagógicos e tecnológicos na grande maioria das escolas, de professores muitas vezes despreparados em sala de aula para atender suas especificidades, da escassez de acessibilidade na sociedade, da existência de preconceitos que estabelecem a deficiência como incapacidade - ainda concebem a vaga para estudantes com deficiências como um privilégio e não como um direito. Como bem lembra Amaral (1994), a deficiência é uma condição global distribuída em duas condições: deficiência primária (deficiência e incapacidade) e deficiência secundária (desvantagem). A deficiência secundária está ligada ao conceito de desvantagem, que está ligada à leitura social, ao que é instituído e dado como "normal". Assim, as chamadas "deficiências secundárias", ou seja, aquelas criadas socialmente acabam por estigmatizar e até impor a superação dos limites próprios da deficiência e dos que lhe são impostos pela própria representação de "ser deficiente".

Com relação às condições de permanência vivenciadas pelos alunos entrevistados, inicialmente solicitou-se que estes descrevessem seu percurso acadêmico na Universidade: se ocorreram reprovações, trancamentos e se foi necessário recursos diferenciados, tanto na sala de aula quanto na realização das avaliações. Dois dos participantes relataram que enfrentaram dificuldades no primeiro ano de seus cursos e tiveram um índice de aproveitamento inferior a $50 \%$. Um destes estudantes teve sérios problemas de saúde e o outro, por timidez, não comunicou aos professores que era surdo ${ }^{20}$. Atualmente esses dois alunos já superaram as dificuldades iniciais e estão acompanhando o percurso acadêmico de seus cursos. Os demais alunos afirmaram que estão acompanhando seus cursos normalmente.

Observou-se pelos relatos que um dos fatores que tem colaborado positivamente com o percurso acadêmico dos alunos, sobretudo daqueles que possuem necessidades mais específicas, tem sido as adaptações e recursos utilizados pelos professores na sala de aula.

Milton afirma que na maioria das vezes suas provas são gravadas: "o professor lê a prova que é gravada, vou para outra sala, escuto, gravo as respostas da prova e o professor ouve depois". Jorge diz que "a maioria de minhas provas são ampliadas". Leonardo, por sua vez, relata que em várias disciplinas necessita de prova digitalizada: "o professor grava a prova em um pen drive, eu

${ }^{20}$ Esta é uma situação que necessita ser revista, pois o NAPNE envia ofício e realiza contato com as coordenações de curso após o registro acadêmico dos estudantes com deficiência. 
a salvo em meu computador num programa específico, completo então a prova, salvo novamente no pen drive e devolvo ao professor". Já Rogério afirma: "faço muitos trabalhos e os entrego de forma impressa, e faço provas orais, conforme as disciplinas e de acordo com cada professor.".

Por outro lado, não resta dúvida que desenvolver e administrar procedimentos de avaliação que forneçam resultados válidos e permitam inferências válidas e decisões para alunos com necessidades educacionais especiais representam o grande desafio para os professores na atualidade. Cada vez mais é necessário que líderes educacionais e professores busquem estratégias, técnicas, políticas e diretrizes para avaliar os alunos para os quais os instrumentos de avaliação tradicionais não são eficazes (RUSSELL; KAVANAUGH, 2011).

Segundo o depoimento dos participantes, os professores não estão alheios à inclusão dos alunos com deficiência na Universidade e demonstram cuidados referentes às especificidades educacionais deste alunado. Esta situação é relevante, principalmente ao se comparar com o estudo realizado por Moreira (2004) que constatou, ao entrevistar nove alunos com deficiência na UFPR, que a queixa geral destes alunos era de que os professores hesitavam em se aproximar e discutir abertamente os encaminhamentos didático-pedagógicos necessários aos mesmos, o que interferia diretamente do processo de ensino-aprendizagem dos estudantes. Leyser, Grenberger e Sharoni (2011), por sua vez, constataram mudanças nas atitudes de professores universitários relacionadas com alunos com deficiências, em um período de 10 anos. Verificaram que a maioria deles expressa interesse em adquirir informações relacionadas com estes estudantes e tem demonstrado atitudes significativamente mais positivas em relação ao alunado especial do que tinha há dez anos.

Com relação às principais dificuldades e limitações encontradas na Universidade que possam interferir na permanência e na inclusão do alunado com NEE, os entrevistados apontam aspectos positivos e também situações que merecem ser revistas, principalmente no que se refere à acessibilidade.

Segundo o Decreto 5.296/04 acessibilidade significa a condição para utilização, com segurança e autonomia, total ou assistida, dos espaços, mobiliários e equipamentos urbanos, das edificações, dos serviços de transporte e dos dispositivos, sistemas e meios de comunicação e informação, por pessoa portadora de deficiência ou com mobilidade reduzida.

Leonardo afirma que inicialmente o acesso à Universidade era muito complicado, pois havia "muitas calçadas quebradas ao redor do campus e no campus, galhos de árvores muito baixos e no caminho, placas colocadas muito baixas e em locais inadequados, não pensadas para um deficiente visual".

Vilmar esclarece que há vaga preferencial para veículo no local das aulas, mas existe uma escada de acesso do estacionamento interno ao prédio que difi- 
culta sua locomoção. Para Jorge há falta de rampas e algumas são inadequadas. Por outro lado, ele afirma que no restaurante universitário sempre "há um funcionário que me auxilia para servir o prato e na biblioteca existe adaptação e tem funcionários que alcançam os livros para mim”.

Rogério é o único aluno entrevistado que está concluindo o curso e ao avaliar as principais barreiras encontradas na universidade, lembrou que inicialmente, em 2006, foram muitas as dificuldades. Segundo ele "não havia na coordenação e nos laboratórios programas para cegos, os elevadores não tinham sensores e nem identificadores em Braille. Isto já foi superado”.

Todos os depoimentos dos participantes apontam que a Universidade precisa aprimorar principalmente a acessibilidade física, pois esta incide diretamente na inclusão educacional e social dos alunos. Mesmo que as condições de acessibilidade nos laboratórios, biblioteca e restaurante universitário demonstrem condições favoráveis aos alunos com deficiência é preciso investir e oferecer igualdade de condições para acesso de todos os alunos (MANZINI et al., 2003; PAGLIUCA, 2007). As barreiras arquitetônicas devem ser visualizadas não apenas como um conjunto de rampas e medidas a serem respeitadas, mas como uma filosofia geral de acolhimento, conforto e facilidades em todas as dependências dos edifícios (RODRIGUES, 2004).

Os eixos de análise referentes ao ingresso e permanência dos alunos são elementos fundamentais para avaliar as políticas inclusivas na Universidade. Entretanto, neste último eixo de análise, indagou-se de forma mais direta este aspecto a partir da perspectiva dos alunos com deficiência. Todos os respondentes deram sugestões para aperfeiçoar as ações da Universidade. Cinco dos alunos consideram que a Universidade está assegurando um processo educacional inclusivo, os outros dois alunos consideram que em parte isto está ocorrendo. Observou-se que os alunos são unânimes quanto à importância do núcleo responsável pelo atendimento das necessidades educacionais especiais na instituição (NAPNE). Enfatizam, todavia, que deveria haver uma unidade NAPNE em todos os campi da Universidade. A questão da acessibilidade física foi novamente retomada por quatro dos alunos, como um aspecto importante para garantir uma política mais inclusiva na Instituição. Aspectos como rampas, adaptação de bebedouros, sinalizações em Braille nas dependências da Universidade foram apontadas como fragilidades existentes na acessibilidade.

Salienta-se que Rogério e Leonardo chamam a atenção para a importância dos professores, técnicos administrativos e colegas possuírem mais conhecimentos sobre as necessidades educacionais especiais. Leonardo afirma que "existe uma inexperiência por parte dos professores e dos alunos de como adaptar conteúdos". Por sua vez, Rogério assegura que "os técnicos administrativos e os professores precisam de maiores informações sobre as deficiências, é preciso qualificação”. 
Particularmente a questão da formação inicial ou continuada dos professores da educação e do ensino superior com bases inclusivas pode ser considerada como um dos grandes entraves para inclusão dos alunos com deficiência. Apesar da Universidade exercer um papel fundamental neste contexto, ainda há um grande vazio em programas ou projetos que envolvam ações relacionadas à qualificação de seu corpo docente em propostas mais inclusivas. Leyser, Grenberger e Sharoni (2011) constataram que atualmente o corpo docente ainda apresenta formação limitada na área da deficiência e pouco conhecimento em habilidades e adaptações para trabalhar com alunos com NEE. Os autores citados enfatizam a necessidade óbvia de maior formação para o corpo docente no ensino superior e evidenciam a grande responsabilidade de gestores, diretores e demais responsáveis, no planejamento, coordenação, implementação e avaliação destas atividades.

Neste sentido, Almeida (2005) adverte que:

A preocupação com a formação do sujeito crítico e consciente de seu processo histórico e cultural é base necessária para a formação acadêmica e, a partir dessa formação, construir um novo projeto social, no qual a compreensão do sujeito com necessidades especiais seja incorporada como reconhecimento de suas capacidades e não de suas dificuldades. (ALMEIDA, 2005, p. 14)

\section{Considerações finais}

O presente estudo demonstrou que não é tarefa simples para a Universidade, porém é possível caminhar na direção de uma educação inclusiva. Apesar dos avanços das políticas de ingresso destinadas aos alunos com deficiência, desenvolvidas na Universidade Federal do Paraná há quase duas décadas, o grande desafio imposto ainda é a constante avaliação desse processo. De igual modo, as ações e encaminhamentos destinados à garantia da permanência desses estudantes na Instituição precisam ser constantemente revistos. Para tanto, a participação e o engajamento dos mesmos é crucial para assegurar seus direitos $\mathrm{e} o$ atendimento às suas necessidades.

De um lado a universidade é locus do conhecimento, são de sua competência a produção científica e a articulação com as distintas áreas do saber; mas, de outro, deve ser também o locus da pluralidade, da diversidade e do respeito às diferenças. 
Enfim, uma universidade inclusiva só é possível no caminhar em busca da mudança que vai eliminando barreiras de toda ordem, desconstruindo conceitos, preconceitos e concepções segregadoras e excludentes. É um processo que nunca está finalizado, mas que, coletivamente, deve ser constantemente enfrentado.

\section{REFERÊNCIAS}

ALMEIDA, C. E. M. Universidade, educação especial e formação de professores. Caxambu: Anped, 2005.

ALMEIDA, M. I. de. Ações organizacionais e pedagógicas dos sistemas de ensino: políticas de inclusão? In: ROSA, D. E. G.; SOUZA, V. C. de. Políticas organizativas e curriculares, educação inclusiva e formação de professores. Rio de Janeiro: DP\&A, 2002.

AMARAL, L. A. Pensar a diferençaldeficiência. Brasília: CORDE - Coordenadoria Nacional para Integração da Pessoa Portadora de Deficiência, 1994.

ANDRÉ, M. D. A.; LÜDKE, M. Pesquisa em educação: abordagens qualitativas. São Paulo: EPU, 1986.

BARDIN, L. Análise de Conteúdo. Lisboa: Edições 70, 2004.

BOGDAN, R.; BIKLEN, S. Investigação qualitativa em Educação: uma introdução à Teoria e aos métodos. Porto: Porto Editora, 2003.

BRASIL. Constituição da República Federativa do Brasil. Brasília: Imprensa Oficial, 1988.

. Declaração Mundial sobre Educação para Todos: plano de ação para satisfazer as necessidades básicas de aprendizagem. Tailândia, 1990.

. Declaração de Salamanca e linha de ação sobre necessidades educativas especiais. Brasília: UNESCO, 1994.

. Decreto n. 5.296, 2 de dezembro de 2004. Regulamenta as Leis $\mathrm{N}^{\circ} 10.048$, de 8 de novembro de 2000, e a Lei $\mathrm{N}^{\circ} 10.098$, de 19 de dezembro de 2000. Brasília, DF, 2004.Disponível em: <http://www010.dataprev.gov.br/sislex/paginas/23/2004/5296. $\mathrm{htm}>$. Acesso em: 21/01/2011.

. Decreto n. 5.626, de 22 de dezembro de 2005. Dispõe sobre a Língua Brasileira de Sinais - Libras, e o art. 18 da Lei no 10.098, de 19 de dezembro de 2000. Diário Oficial da República Federativa do Brasil. Brasília, 23 dez. 2005.

. Lei n. 9.394, de 20 de dezembro de 1996. Estabelece as diretrizes e bases da educação nacional. Diário Oficial da República Federativa do Brasil. Brasília, 23 dez. 1996. 
. Resolução CNE/CP n. 1, de 19 de fevereiro de 2002. Institui diretrizes curriculares nacionais para a formação de professores da educação básica, em nível superior, curso de licenciatura, de graduação plena. Diário Oficial da República Federativa do Brasil, Brasília, DF, 18 fev. 2002. Disponível em: <http://portal.mec.gov.br/seesp/arquivos/pdf/ res1_2.pdf>. Acesso em: 16/02/2011.

. Ministério da Educação/Instituto Nacional de Estudos e Pesquisas Educacionais Anísio Teixeira (INEP). Censo da Educação Superior de 2007: alunos portadores de necessidades especiais: Dados Estatísticos por cursos de graduação presenciais, por Instituição da Educação Superior. Brasília: INEP, 2007.

. Censo da Educação Especial de 2000 e 2005: evolução da educação especial no Brasil. Dados Estatísticos por estado das matrículas na educação especial. Brasília: INEP, 2000 e 2005.

. Resumo Técnico: Censo da Educação Superior 2007. Brasília: MEC/INEP, 2009. . Números da educação no Brasil 2001. Brasília, 2002.

. Ministério da Educação/Gabinete do Ministro (GM). Aviso Circular $n^{\circ} 277$. Brasília: MEC/GM, 1996.

. Ministério da Educação/Secretaria de Educação Especial (SEESP). Política Nacional de Educação Especial na Perspectiva da Educação Inclusiva. Brasília: MEC, 2008. 2007.

. Programa Incluir. Edital nº 3, de 26 de Abril de 2007. Brasília: MEC/SEESP,

. Decreto n. 3.298. de 20 de dezembro de 1999. Presidência da República. Brasília: PR, 1999.

. Ministério da Educação. Portaria Ministerial n. 1.679/99. Dispõe sobre os requi$\overline{\text { sitos de }}$ acessibilidade à pessoa portadora de deficiência para instruir processos de autorização e reconhecimento de cursos e de credenciamentos de instituições. Brasília, 1999.

.Portaria Ministerial n. 1.793/94. Dispõe sobre a necessidade de complementar os currículos de formação de docentes e outros profissionais que interagem com portadores de necessidades especiais e dá outras providências. Brasília, 1994.

CASTRO, S. Ingresso e permanência de alunos com deficiência em universidades públicas brasileiras. Tese (Doutorado em Educação) - Universidade Federal de São Carlos, São Carlos, 2010.

CHACON, M. C. M. Formação de recursos humanos em educação especial: respostas das universidades à recomendação da portaria ministerial $n^{\circ} 1.793$, de 27 de dezembro de 1994. Tese (Doutorado em Educação) - Universidade Estadual Paulista, 2001.

LEYSER, Y.; GREENBERGER, L.; SHARONI, V. International Journal of Special Education, v. 26, n. 1, p. 162-174, 2011. Disponível em: <http://www.eric.ed.gov/PDFS/ EJ921202.pdf.> Acesso em: 10/2/2011. 
MANZINI, E. J. et al. Acessibilidade em ambiente Universitário: identificação e quantificação de barreiras arquitetônicas. In: MARQUEZINI, M. C. et al. (Org.). Educação física, atividades lúdicas e acessibilidade de pessoas com necessidades especiais. Londrina: UEL, 2003. p. 185-192.

MINAYO, M. C. de S. Pesquisa social: teoria, método e criatividade. Petrópolis: Vozes, 1992.

MOREIRA, L. C. Universidade e alunos com necessidade educacionais especiais: das ações institucionais às práticas pedagógicas. 233 f. Tese (Doutorado em Educação) Faculdade de Educação, Universidade de São Paulo, São Paulo, 2004.

. Iniciativas, atividades e ações da UFPR acerca da pessoa com necessidades especiais. Cadernos de Educação Especial, v. 2. Curitiba: Universidade Federal do Paraná, 2000.

ODEH, M. M. O atendimento educacional para crianças com deficiências no hemisfério sul e a integração não planejada: implicações para as propostas de integração escolar. Revista Brasileira de Educação Especial, v. 1, n. 6, p. 27-42, 2000.

PAGLIUCA L. M. F. et al. Acessibilidade e deficiência física: identificação de barreiras arquitetônicas em áreas internas de hospitais de Sobral, Ceará. Revista da Escola de Enfermagem, v. 41, n. 4, p. 581-588, 2007.

RODRIGUES, D. A. Inclusão na Universidade: Limites e possibilidades da construção de uma universidade inclusiva. Revista Educação Especial, n. 23, 2004. Disponível em: < http://coralx.ufsm.br/revce/ceesp/2004/01/a1.htm > Acesso em: 20/2/2011.

RUSSELL, Michael; KAVANAUGH, Maureen. Assessing Students in the Margin: Challenges, Strategies, and Techniques. Charlotte, NC: Information Age Pub., 2011.

SECRETARIA DE EDUCAÇÃO ESPECIAL (SEESP). Apresentação. Brasília, 2010 Disponível em: $<$ http://portal.mec.gov.br/index.php?option=com_content\&view=articl e\&id=288\&Itemid=824>. Acesso em: 13/5/2010.

UNESCO. $48^{a}$ Conferência internacional sobre a Educação. Genebra, 2008

UNIVERSIDADE FEDERAL DO PARANÁ. Secretaria dos Órgãos Colegiados. Resolução n. ${ }^{\circ}$ 27/91-CEPE. Curitiba-Pr, 1991.

. Secretaria dos Órgãos Colegiados. Resolução n ${ }^{\circ}$ 70/08-COUN-Aprimora as políticas de ingresso e permanência de pessoas com deficiências na UFPR. Curitiba-PR, 2008.

Texto recebido em 08 de fevereiro de 2011.

Texto aprovado em 04 de abril de 2011. 